\title{
Nutrition Screening and Referrals in Two Rural Australian Oncology Clinics
}

\author{
Emma Bohringer, Leanne Brown \\ University of Newcastle Department of Rural Health, Tamworth, Australia \\ Email: emma.bohringer@newcastle.edu.au
}

How to cite this paper: Bohringer, E. and Brown, L. (2016) Nutrition Screening and Referrals in Two Rural Australian Oncology Clinics. Food and Nutrition Sciences, 7, 1070-1081.

http://dx.doi.org/10.4236/fns.2016.712103

Received: September 11, 2016

Accepted: October 14, 2016

Published: October 17, 2016

Copyright $\odot 2016$ by authors and Scientific Research Publishing Inc. This work is licensed under the Creative Commons Attribution International License (CC BY 4.0).

http://creativecommons.org/licenses/by/4.0/ (c) (i) Open Access

\begin{abstract}
Malnutrition is common, and is a significant contributing factor to morbidity and mortality in the oncology setting. Previous research suggests that dietetic services in rural oncology clinics need to be well organized, timely and flexible with routine screening processes. In the absence of routine nutrition screening, it is hypothesized that oncology patients are only referred to dietetic services when malnutrition is overt or advanced. The aim of this study was to describe and compare dietetic services in two rural Australian oncology clinics and investigate nutrition screening and referral practices to determine if oncology patients at nutritional risk were appropriately referred. A retrospective file audit of medical and treatment records was conducted for a sample of oncology patients to determine the proportion of patients at risk of malnutrition by using the Malnutrition Screening Tool retrospectively. Dietetic treatment statistics and key stakeholders were consulted to compare dietetic service provision across the two sites. Seventy-eight percent of patients $(n=129)$ were retrospectively determined to be at nutritional risk during the study period, however, only $66 \%$ of these patients were referred to a dietitian. Dietetic treatment statistics varied across the two sites ranging from 26 to 62 treated patients, an average of 2.4 to 4.5 dietetic interventions per patient and an average difference in patient intervention time of 62 minutes during the 12-month study period. This study confirmed findings from previous research, highlighting that without routine nutrition screening in oncology, at least one third of patients at nutritional risk were failing to be identified and referred to dietetic services for appropriate treatment. Routine nutrition screening should be implemented to standardise and prioritise dietetic service provision, and oncology specific funding should be allocated to the dietetic service to ensure that staffing is adequate to provide a timely service.
\end{abstract}

\section{Keywords}

Malnutrition, Malnutrition Screening Tool (MST), Nutrition Screening, Oncology, Rural 


\section{Introduction}

Cancer and its associated treatments often have adverse effects on a patient's nutrition status and can result in malnutrition [1] [2]. Malnutrition is reported to affect up to $80 \%$ of oncology patients [2]-[5] and is a significant contributing factor in up to $20 \%$ of cancer mortalities [4] [6]. Malnutrition is clinically defined as the unintentional loss of $\geq 5 \%$ of Usual Body Weight (UBW) in one month, or $\geq 10 \%$ of UBW in six months [7]. At this level, a malnourished patient has a shorter life expectancy than a patient with a similar cancer, at a similar stage, who has remained well-nourished [8]. Recent research has shown that patients who receive regular, proactive, individualised education and counselling from a dietitian during cancer treatment are better able to maintain baseline nutrition status and quality of life when compared to patients who receive generic nutrition advice or written information from oncology staff [3] [4] [7] [9]-[13].

Dietitians in rural health care facilities face a number of unique issues when providing services to oncology outpatients and oncology specific dietetic positions or FullTime Equivalent (FTE) hours are often not funded [3] [4]. Rural oncology clinics tend to service large geographical areas, with some patients travelling long distances to attend the same-day outpatient service [3]. If dietetic services are not available when a patient is scheduled for oncology treatment, nutritional interventions may be missed or delayed. Access to dietetic services may then result in additional travel burden for patients, which may not be feasible for rural or remote patients, particularly those suffering ill effects of chemotherapy.

The present study investigated dietetic services provided in two rural Australian oncology clinics. The study sites are selected as they are two rural public hospitals with oncology treatment services where public health service dietitians provide ad hoc nutrition intervention in the absence of dietetic funding dedicated to the oncology service.

The purpose of this study was to describe and compare the dietetic services provided in the two oncology clinics and to investigate nutrition screening and referral practices of each site to determine if oncology patients at nutritional risk were being appropriately referred to dietetic services.

\section{Methods}

This study involved a retrospective audit of service provision data and clinical treatment records for a convenience sample of patients over the age of eighteen years who attended two rural Australian oncology clinics for cancer treatment over a 12-month period. Eligible subject files were identified via oncology treatment statistics on the electronic clinical recording system (ARIA) used in the oncology sector of the Australian public hospital network (Varian Medical Systems, California USA). Patient files were separated into two groups: 1) The Dietetic Treatment group (DTx) included patients who received dietetic intervention during their outpatient cancer treatment. These were identified through dietetic treatment statistics on the Allied Health Management Information System (AHMIS). 2) The Non-Dietetic Treatment group (NDTx) who consisted of a sample of patients who received cancer treatment in the same 12- 
month period, without any dietetic intervention. These were randomly selected, proportionately from both sites, using an online random number generator [14].

Ethics approval was sought from the local health district ethics board, however was not required for this clinical audit.

Data collection at the two sites was conducted from May to August 2011. Details about each health service were obtained from publicly available documents and personal communication with local health managers. Dietetic service statistics were obtained from the AHMIS database. Clinical and demographic data was collected from the medical record and ARIA database for all study subjects. Dietitians' paper-based treatment files were accessed for treatment details for patients in the DTx group. Data was used to retrospectively calculate the patients' risk of malnutrition using the malnutrition screening tool (MST) [15].

The MST is an effective way to identify oncology patients who are or may be at nutritional risk [5] [16]. The MST contains questions on unintentional weight loss and changes in appetite to generate a nutritional risk score between zero and five [5]. An MST score of two or more indicates the patient may be at nutritional risk and should be referred to a dietitian for a complete nutrition assessment and intervention as required [15]. Patients receiving a score below two should be re-screened at regular intervals during treatment to monitor changes in nutritional status [15] [17]. The MST has been validated for use in oncology outpatients receiving chemotherapy [5] and radiotherapy [15], and shows a high sensitivity and specificity for predicting the Subjective Global Assessment (SGA) [15] [18] [19], later updated to the Patient-Generated SGA (PG-SGA) which is considered the gold standard nutrition screening and assessment tool in the oncology setting [16] [19].

In the present study, the MST was used retrospectively to calculate a malnutrition risk score using data collected from the clinical record based on two time points; initial and final presentation to oncology in the 12-month period. Initial MST scores were calculated using the subject's first recorded body weight, along with weight and appetite history recorded for the preceding six months. Final MST scores were calculated using the subject's final body weight recorded in the 12-month period, along with weight and appetite history recorded for the preceding six months. Mid-way MST scores were also calculated, as described above, for study subjects who attended oncology for the entire 12-month study period. The type and frequency of dietetic interactions (occasions of service, OOS) for subjects in the DTx group was used to assess the adequacy of dietetic services provided to rural oncology clinics. The residential postcode of each study subject, collected from the ARIA database, was used to calculate the distance (in $\mathrm{km}$ ) required to travel to reach the treatment facility, via an online travel calculator [20].

Statistical analyses were performed using JMP ${ }^{\circledR}$ Version 9 (SAS Institute Inc., North Carolina USA). Two sample t-tests were performed to detect differences in mean MST scores between the DTx and NDTx groups at the accepted significance level of $\mathrm{P}<0.05$. Chi square tests were performed on categorical data, such as cancer type, to detect differences between groups and sites. Descriptive statistics such as counts, proportions, 
means and standard deviations were also calculated using JMP ${ }^{\circledR}$ and used to analyse and present data. All data collection and calculation of nutritional risk scores was conducted by the first author to ensure consistency.

\section{Results}

An initial search identified 270 potential patient files. Of these, 208 were suitable for retrieval and audit, however only 129 were included in the final study sample. Primary reasons for file exclusion were; insufficient data in treatment record(s), one or more of the treatment records could not be accessed during the data collection period or the patient was attending the oncology clinic for observation or non-active treatment only. Fifty-one subject files from Site 1 and 78 from Site 2 provided a representative sample. The combined total from both sites resulted in 73 subject files in the DTx group and 56 in the NDTx group.

Table 1 presents key characteristics of the two study sites and the dietetic service provided to the outpatient oncology clinics. Dietitians at Site 1 provided an average of

Table 1. Key characteristics of the study sites and dietetic service provided in the study period.

\begin{tabular}{|c|c|c|}
\hline Characteristics of Study Sites & Rural Site 1 & Rural Site 2 \\
\hline Number of inpatient beds & 270 & 154 \\
\hline Number of outpatient chemotherapy chairs & 9 & 6 \\
\hline Number of FTE clinical dietitians & 4.2 & 2.7 \\
\hline Location of oncology & External to dietetics & Co-located with dietetics \\
\hline Access to ARIA & No & Yes \\
\hline \multicolumn{3}{|l|}{ Characteristics of dietetic service provision } \\
\hline \multicolumn{3}{|l|}{ Oncology patients seen by a dietitian } \\
\hline \multicolumn{3}{|l|}{ Number of subjects (proportion) } \\
\hline Total & 26 & 62 \\
\hline Excluded & $2(8 \%)$ & $13(21 \%)$ \\
\hline Included in Study & $24(92 \%)$ & $49(79 \%)$ \\
\hline \multicolumn{3}{|l|}{ Occasions of Service (OOS), per patient } \\
\hline \multicolumn{3}{|l|}{ Number of subjects (proportion) } \\
\hline 1 OOS & $11(46 \%)$ & $9(18 \%)$ \\
\hline 2 oOs & $8(33 \%)$ & $7(14 \%)$ \\
\hline 3 oos & $1(4 \%)$ & $10(20 \%)$ \\
\hline 4 OOS & 0 & $3(6 \%)$ \\
\hline $5+$ OOS & $4(17 \%)$ & $16(33 \%)$ \\
\hline Not Recorded & 0 & $4(8 \%)$ \\
\hline Mean $( \pm S D)$ & $2.4( \pm 2.3)$ & $4.5( \pm 4.5)$ \\
\hline \multicolumn{3}{|c|}{ Combined duration of dietetic interventions (minutes) } \\
\hline Total & 2265 & 9210 \\
\hline Mean, per patient & $87( \pm 130.5)$ & $149( \pm 128)$ \\
\hline Mean, per week & 44 & 177 \\
\hline Mean FTE hours, per week & 0.02 & 0.08 \\
\hline
\end{tabular}


2.4 OOS $( \pm 2.3)$ and 87 minutes $( \pm 130.5$ minutes $)$ with each patient. Dietitians at Site 2 provided an average of 4.5 OOS $( \pm 4.5)$ per patient and spent an average of 149 minutes ( \pm 128 minutes) with each patient over the 12 -month study period. Dietitians at Site 1 provided an average of 44 minutes ( 0.73 hours) per week compared to 177 minutes (2.95 hours) per week at Site 2. Twenty-five percent of study subjects in the DTx group at Site 1 were actively discharged from the dietetic service, compared to $51 \%$ from Site 2.

Table 2 shows the characteristics of the study sample. The mean age for all subjects was 65 years $( \pm 10.3)$ and males represented $56 \%$ of the study population. The primary cancers treated were bowel cancer (33\%), lymphoma/myeloma (15\%), lung (12\%) and head and neck cancer (12\%). Although some differences in cancer type existed between the DTx and NDTx groups and the two study sites these were not statistically significant $(P>0.05)$. There were no significant differences for age or gender between groups or sites $(P>0.05)$. The mean duration of active oncology treatment over the 12 months was 6.5 months at Site 1 and 6.4 months at Site 2. The mean distance required for study subjects to travel to access health services was $51 \mathrm{~km}( \pm 72.3 \mathrm{~km})$ for Site 1 and $29 \mathrm{~km}$ $( \pm 22.5 \mathrm{~km})$ for Site 2 . The difference in mean travel distance was not statistically significant $(\mathrm{P}=0.05)$, however seven $(15 \%)$ of the subjects from Site 1 lived $>100 \mathrm{~km}$ from the health service, compared to just one subject from Site 2 (Figure 1).

Table 2. Characteristics of the study sample.

\begin{tabular}{lccccc}
\hline & $\begin{array}{c}\text { Rural Site } 1 \\
\mathbf{n}=\mathbf{5 1}\end{array}$ & $\begin{array}{c}\text { Rural Site } 2 \\
\mathbf{n}=\mathbf{7 8}\end{array}$ & $\begin{array}{c}\text { DTx } \\
\mathbf{n}=\mathbf{7 3}\end{array}$ & $\begin{array}{c}\text { NDTx } \\
\mathbf{n}=56\end{array}$ & $\begin{array}{c}\text { All Subjects } \\
\mathbf{n}=\mathbf{1 2 9}\end{array}$ \\
\hline Age in years & & & & & \\
Mean (SD) & $63.9( \pm 10.8)$ & $65.7( \pm 10.1)$ & $66.2( \pm 9.6)$ & $63.5( \pm 11.1)$ & $65.0( \pm 10.3)$ \\
Gender & & & & & \\
Number of subjects (proportion) & & & & & \\
Male & $28(55 \%)$ & $44(56 \%)$ & $38(52 \%)$ & $34(61 \%)$ & $72(56 \%)$ \\
Female & $23(45 \%)$ & $34(44 \%)$ & $35(48 \%)$ & $22(39 \%)$ & $57(44 \%)$ \\
Primary Cancer treated & & & & & \\
number of subjects (proportion) & & & & & \\
Bowel & $16(31 \%)$ & $26(33 \%)$ & $22(30 \%)$ & $20(36 \%)$ & $42(33 \%)$ \\
Breast & $6(12 \%)$ & $5(6 \%)$ & $7(10 \%)$ & $4(7 \%)$ & $11(9 \%)$ \\
Cervical/Endometrial/Ovarian & $2(4 \%)$ & $2(3 \%)$ & $2(3 \%)$ & $2(4 \%)$ & $4(3 \%)$ \\
Gastric & $4(8 \%)$ & $4(5 \%)$ & $5(7 \%)$ & $3(5 \%)$ & $8(6 \%)$ \\
Head \& Neck & $9(18 \%)$ & $7(9 \%)$ & $13(18 \%)$ & $3(5 \%)$ & $16(12 \%)$ \\
Liver & $3(6 \%)$ & $3(4 \%)$ & $2(3 \%)$ & $4(7 \%)$ & $6(5 \%)$ \\
Lung & $3(6 \%)$ & $12(15 \%)$ & $8(11 \%)$ & $7(13 \%)$ & $15(12 \%)$ \\
Lymphoma/Myeloma & $3(6 \%)$ & $16(21 \%)$ & $10(13 \%)$ & $9(16 \%)$ & $19(15 \%)$ \\
Prostate & $1(2 \%)$ & $1(1 \%)$ & $2(3 \%)$ & $4(7 \%)$ & $2(2 \%)$ \\
Other ${ }^{\dagger}$ & $4(8 \%)$ & $2(3 \%)$ & $2(3 \%)$ & $4(7 \%)$ & $6(5 \%)$ \\
\hline
\end{tabular}

†Other cancer types include bladder and kidney cancer. 

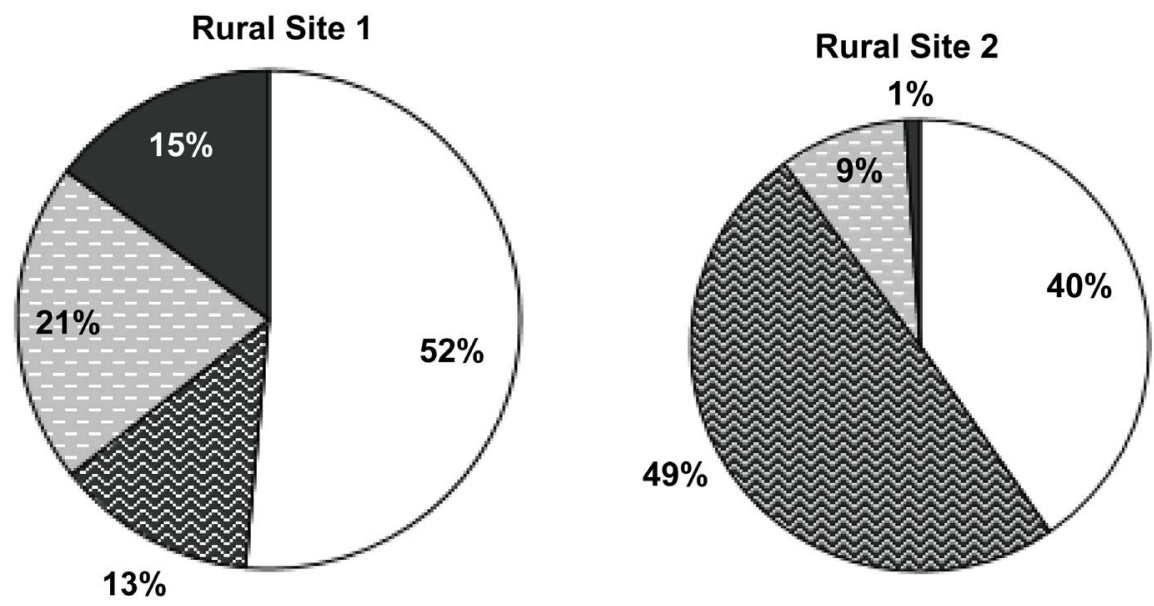

Figure 1. A comparison of the distance (in $\mathrm{km}$ ) travelled by patients to Site 1 and Site 2 Health Services. $\square 0-20 \mathrm{~km}$; 圆 $21-50 \mathrm{~km}$; $\square 51-100 \mathrm{~km}$; $\square>100 \mathrm{~km}$. Values expressed as the proportion of study subjects from each site. Mean distance $( \pm S D)$ : Site $151 \mathrm{~km}( \pm 72.3 \mathrm{~km})$; Site 2 $29 \mathrm{~km}( \pm 22.5 \mathrm{~km})$.

Initial and final MST scores for all study subjects are presented in Table 3. At initial assessment, 63 of the 73 (86\%) subjects in the DTx group and 28 of the $56(50 \%)$ subjects in the NDTx group were at risk of malnutrition, as defined by an MST score of $\geq 2$. Mean initial MST scores were $2.4( \pm 1.2)$ and $1.3( \pm 1.3)$ for the DTx and NDTx group respectively. This difference was statistically significant $(\mathrm{P}<0.0001)$. At final assessment, $24(33 \%)$ subjects in the DTx group and $12(21 \%)$ subjects in the NDTx group were at risk of malnutrition, according to MST. Mean final MST scores were $1.9( \pm 1.4)$ for the DTx group and $(0.9 \pm 1.2)$ for the NDTx group. This represents an improvement in nutritional risk indicators for $53 \%$ of subjects in the DTx group compared to $29 \%$ in the NDTx group. This difference was also statistically significant $(\mathrm{P}<0.0001)$. Overall, 101 of the 129 (78\%) study subjects were determined by MST to be at risk of malnutrition at one or more time points during active cancer treatment over the 12month period, however only $67(66 \%)$ of these study subjects had been referred to a dietitian. Thirty-four of the 56 (61\%) subjects in the NDTx group were identified to be at risk of malnutrition at one or more study time points. Furthermore, eight of the 28 (29\%) study subjects in the NDTx group with an initial MST score $\geq 2$ had a final MST score of $\geq 2$ and had not been referred to a dietitian. The mean change in MST score was a decrease of $0.5( \pm 1.5)$ in the DTx group and $0.4( \pm 1.6)$ in the NDTx group respectively. A decrease in MST score relates to a decreased nutritional risk and is therefore a positive outcome. Statistical significance could not be determined for mean change in MST score due to insufficient sample size.

\section{Discussion}

Malnutrition continues to be a major issue in the oncology setting and remains under-recognised and under-treated [6] [17] [21]. This is despite the well-known consequences of untreated malnutrition [8] [22]-[24] and the evidence to support proactive 
Table 3. A comparison of nutritional risk indicators between treatment groups as defined by MST score.

\begin{tabular}{|c|c|c|}
\hline & $\begin{array}{c}\text { DTx } \\
\mathrm{N}=73\end{array}$ & $\begin{array}{l}\text { NDTx } \\
\mathrm{N}=56\end{array}$ \\
\hline & Number of subjects (proportion) & Number of subjects (proportion) \\
\hline \multicolumn{3}{|c|}{ Initial MST Score } \\
\hline 0 & $6(8 \%)$ & $25(45 \%)$ \\
\hline 1 & $4(5 \%)$ & $3(5 \%)$ \\
\hline 2 & $31(42 \%)$ & $18(32 \%)$ \\
\hline 3 & $22(30 \%)$ & $9(16 \%)$ \\
\hline 4 & $4(5 \%)$ & 0 \\
\hline 5 & $6(8 \%)$ & $1(2 \%)$ \\
\hline Total $\geq 2$ & $63(86 \%)$ & $28(50 \%)$ \\
\hline Mean (SD) & $2.4( \pm 1.2)^{\star}$ & $1.3( \pm 1.3)$ \\
\hline \multicolumn{3}{|c|}{ Final MST Score } \\
\hline 0 & $16(22 \%)$ & $29(52 \%)$ \\
\hline 1 & $15(21 \%)$ & $15(27 \%)$ \\
\hline 2 & $12(16 \%)$ & $4(7 \%)$ \\
\hline 3 & $3(4 \%)$ & $7(13 \%)$ \\
\hline 4 & $6(8 \%)$ & 0 \\
\hline 5 & $3(4 \%)$ & $1(2 \%)$ \\
\hline Total $\geq 2$ & $24(33 \%)$ & $12(21 \%)$ \\
\hline Mean (SD) & $1.9( \pm 1.4)^{*}$ & $0.9( \pm 1.2)$ \\
\hline \multicolumn{3}{|c|}{ Change in MST Score } \\
\hline${ }^{\dagger}$ Mean $(\mathrm{SD})$ & $-0.5( \pm 1.5)$ & $-0.4( \pm 1.6)$ \\
\hline
\end{tabular}

MST $=$ Malnutrition Screening Tool $;{ }^{*} \mathrm{P}<0.05$ compared to NDTx group. ${ }^{\dagger}$ A negative value for mean change in MST score indicates a decrease in score which relates to a decrease in nutritional risk.

nutrition intervention [3] [11] [21] [25]. This study identified 78\% of study subjects in two rural Australian oncology clinics to be at risk of malnutrition according to a retrospective application of the MST. One third of those determined to be at nutritional risk failed to be referred to dietetic services. Results from other similar studies by Planas et al. (2016) [26] and Abbott et al. (2014) [27] have found varying results. In a sub-analysis of data from the PREDyCES study [28], Planas showed that at least $67 \%$ of oncology inpatients were at nutritional risk at discharge according to the Nutrition Risk Screening ${ }^{\oplus}-2002$ tool $\left(\mathrm{NRS}^{\oplus}-2002\right)$ and had not received nutrition support during admission [26]. Abbott reported that $41.2 \%$ of the patients in their study who were identified via nutrition assessment (PG-SGA) to be malnourished were not known to dietetic services [27]. In prospective studies using the MST in the oncology setting, Ferguson et al. (1999) [15] and Isenring et al. (2006) [5] identified that $28 \%$ and $32 \%$ of participants 
respectively were at risk of malnutrition. The similar results found by Ferguson and Isenring when using the MST prospectively suggests the retrospective application of the MST tool based on data recorded in the medical record in this study did not significantly limit the results. Differences in nutritional risk identified between studies may be due to the study samples [5] [15], proportion of female participants [15], mean age [5] [15], and types of cancer treated [5] [15]. The prevalence of malnutrition is known to be higher in patients with cancers of head or neck or gastrointestinal system [2] [4] [22]. Further research is required to determine whether age or gender has a significant impact on malnutrition [1] [4].

Dietetic services provided in the two rural oncology clinics in this study were found to be variable, and lacked consistent or validated nutrition screening practices and referral to dietetic services. In the absence of consistent and proactive nutrition screening it has been suggested that patients are typically referred to a dietitian when they have overt signs of malnutrition such as significant unintentional weight loss or reduced oral intake, by which stage malnutrition may be advanced [3] [19]. Current evidence based guidelines propose that routine screening for malnutrition should occur in the acute and community setting to improve the identification of malnutrition risk and to allow for nutritional care planning [17]. Patients who are determined through a formal nutrition assessment to be malnourished should be reviewed by a dietitian at least fortnightly to monitor energy, protein and fluid requirements, and for monthly anthropometric monitoring [17]. The absence of oncology specific dietetic funding for the two sites at the time of this study required that dietetic services for oncology be provided by drawing upon resources allocated to other priority areas, potentially compromising those services.

A number of factors have been identified that may account for the difference in dietetic referrals between the two sites in this study. Oncology nursing and support staff in Site 2 were described as 'nutritionally aware' and proactive in providing dietetic referrals, although these referrals were not based on a consistent, validated nutrition screening process (Pomplun, J., Site 2, 2011, personal communication). The use of a formal dietetic referral pathway, allowing consistency and documentation of referrals, may also have contributed to the higher number of patients referred to dietetic services at Site 2. Dietetic and oncology service departments in Site 2 are co-located and this may help to facilitate opportunistic referrals, patient monitoring and follow-up. While a number of strategies continue to be trialed by dietitians in Site 1 to increase nutrition awareness, improve interdisciplinary relationships and streamline dietetic referrals, these were not in place at the time of this study.

A number of factors may also explain the variation in OOS provided per patient between the two sites. The ratio of dietitians to bed numbers was similar across the two hospitals, however, dietitians in Site 1 provided a number of services, such as clinical outreach to other rural sites and supervision of clinical student placements, which were not typically provided at Site 2 . Site 2 had strategies in place to enhance follow-up, including phone or letter based reminders to patients if they had not returned for nutri- 
tion monitoring or if they had not placed an order for nutrition support products as prescribed by the dietitian. These strategies were not consistently undertaken at Site 1, which may have contributed to lower follow-up rates. This may also help explain why a greater proportion of patients in Site 2 were actively discharged from the dietetic service whereas patients in Site 1 were "lost to follow-up". Dietitians in Site 2 had access to ARIA, where they could access a patients' oncology treatment schedule and plan to review a patients' progress at their next treatment. With patient treatment schedules constantly changing due to unplanned hospital admissions and treatment delays [22]-[24], daily access to patient treatment schedules on ARIA may have allowed for better follow-up in this site. The shorter average distance travelled to access services in Site 2 compared to Site 1 may have made opportunities for dietetic follow-up outside the patients' oncology treatment time more feasible and therefore contributed to higher follow-up rates at Site 2. Travel and transport are often cited as barriers to healthcare access, particularly in rural and remote areas where travel distances are great, roads are poorly maintained and public transport options are limited [29] [30]. Travel and transportation issues are associated with a greater burden of disease for patients, and often result in delayed or missed healthcare appointments [31]. A small study conducted in elderly residents of rural Vermont by Nemet and Bailey (2000) found that people who had to travel more than 10 miles $(16 \mathrm{~km})$ to access health services tended to go less frequently than those who had to travel shorter distances [32]. Furthermore, Winters et al. (2006) found that distance had a significant impact on the healthcare decisions of women with chronic illness living in isolated rural areas, and that travel affected them physically, and was a cause of stress [33].

A 2011 unpublished report highlighted the need for dietetic services in rural oncology. This needs assessment compared dietetic staffing across rural and regional oncology clinics and found that facilities similar to those in the present study were funded for 0.5 FTE dietitian(s), which clinic staff believed to be an inadequate level of dietetic service (Holley, T., Houlihan, N., Reed, J., 2011, unpublished work). At the time of data collection for this study, construction had commenced for a new oncology centre at Site 1. The new oncology centre adds seven chemotherapy chairs and two linear accelerators to the existing service, allowing patients who have previously had to travel to major cities for radiotherapy (RTx) to be treated locally [34]. Funding of 0.1FTE dietitian for Radiation Oncology at the centre is not anticipated to meet service demands and is not comparable with other facilities in Australia which average 0.7FTE dietitians per linear accelerator (Holley, T., Houlihan, N., Reed, J., 2011, unpublished work). No dietetic funding has been allocated specifically to dietetic services for Medical Oncology (chemotherapy) (Harris, D., Site 1, 2011 personal communication). In another study, Brown et al. (2008) [3] proposed that dietetic services in rural oncology centres need to be included in full-time position funding as a part-time service is inflexible and therefore likely to be inadequate to meet the needs of patients with varying treatment schedules.

This study was limited by its retrospective nature. Many patient files had to be ex- 
cluded due to insufficient data on weight and nutrition related symptoms. Although this limits the study sample, it highlights a lack of attention given to nutritional factors in the two rural oncology clinics in this study. Potential inconsistencies in the recording of dietetic treatment data in AHMIS may also have contributed to differences in service provision statistics across the two sites in this study.

\section{Conclusion}

Dietetic referrals for patients at nutritional risk in two rural Australian oncology clinics in this study were found to be inconsistent, not based on valid or reliable nutrition screening methods, and insufficient to adequately identify patients who were at nutritional risk and may be malnourished. The implementation of routine nutrition screening in oncology using a validated, scored tool, such as the MST, is recommended. This would allow limited dietetic services to be prioritised to those with the greatest nutritional needs without placing extra burden on oncology staff as the MST can be completed by the patient. The absence of oncology specific dietetic funding for the two sites in this study did not allow for a comprehensive dietetic service for rural oncology patients, and was not consistent with funding allocated for similar, metropolitan based oncology clinics in Australia. A reorientation of current funding may assist dietitians in rural areas to standardise dietetic services to oncology patients. However, it is suggested that dietetic specific oncology funding is required in order to provide comprehensive, individualised nutritional management of rural Australian oncology patients in line with current research and evidence based guidelines, and without compromising dietetic services in other priority areas.

\section{References}

[1] Read, J., Choy, B., Beale, P. and Clarke, S. (2006) An Evaluation of the Prevalence of Malnutrition in Cancer Patients Attending the Outpatient Oncology Clinic. Asia-Pacific Journal of Clinical Oncology, 2, 80-86. http://dx.doi.org/10.1111/j.1743-7563.2006.00048.x

[2] Boltong, A., Loeliger, J. and Steer, B. (2013) Using a Public Hospital Funding Model to Strengthen a Case for Improved Nutritional Care in a Cancer Setting. Australian Health Review, 37, 286-290. http://dx.doi.org/10.1071/AH13010

[3] Brown, L., Capra, S. and Williams, L. (2008) A Best Practice Dietetic Service for Rural Patients with Cancer Undergoing Chemotherapy: A Pilot of a Pseudo-Randomised Controlled Trial. Nutrition \& Dietetics, 65, 175-180. http://dx.doi.org/10.1111/j.1747-0080.2008.00238.x

[4] Creaser, N. (2010) Nutrition Status of Oncology Patients Admitted to a Rural Day Chemotherapy Unit as Measured by the Patient Generated-Subjective Global Assessment. Nutrition \& Dietetics, 67, 231-236. http://dx.doi.org/10.1111/j.1747-0080.2010.01468.x

[5] Isenring, E., Cross, G., Daniels, L., Kellet, E. and Koczwara, B. (2006) Validity of the Malnutrition Screening Tool as an Effective Predictor of Nutritional Risk in Oncology Outpatients Receiving Chemotherapy. Supportive Care in Cancer, 14, 1152-1156. http://dx.doi.org/10.1007/s00520-006-0070-5

[6] Spiro, A., Baldwin, C., Patterson, A., Thomas, J. and Andreyev, H. (2006) The Views and Practices of Oncologists Towards Nutritional Support in Patients Receiving Chemotherapy. 
British Journal of Cancer, 95, 431-434. http://dx.doi.org/10.1038/sj.bjc.6603280

[7] van den Berg, M., Rasmussen-Conrad, E., Wei, K., Lintz-Luidens, H., Kaanders, J. and Merkx, M. (2010) Comparison of the Effect of Individual Dietary Counseling and of Standard Nutritional Care on Weight Loss in Patients with Head and Neck Cancer Undergoing Radiotherapy. British Journal of Nutrition, 104, 872-877. http://dx.doi.org/10.1017/S0007114510001315

[8] Whitman, M. (1999) The Starving Patient: Supportive Care for People with Cancer. Clinical Journal of Oncology Nursing, 4, 121-125.

[9] Isenring, E., Capra, S. and Bauer, J. (2004) Nutrition Intervention Is Beneficial in Oncology Outpatients Receiving Radiotherapy to the Gastrointestinal or Head and Neck Area. British Journal of Cancer, 91, 447-452. http://dx.doi.org/10.1038/sj.bjc.6601962

[10] Odelli, C., Burgess, D., Bateman, L., Hughes, A., Ackland, S., Gillies, J., et al. (2005) Nutrition Support Improves Patient Outcomes, Treatment Tolerance and Admission Characteristics in Oesophageal Cancer. Clinical Oncology, 17, 639-645. http://dx.doi.org/10.1016/j.clon.2005.03.015

[11] Paccagnella, A., Morello, M., Da Mosto, M.C., Baruffi, C., Marcon, M.L., Gava, A., et al. (2010) Early Nutritional Intervention Improves Treatment Tolerance and Outcomes in Head and Neck Cancer Patients Undergoing Concurrent Chemoradiotherapy. Supportive Care in Cancer, 18, 837-845. http://dx.doi.org/10.1007/s00520-009-0717-0

[12] Ravasco, P., Monteiro-Grillo, I., Marquez Vidal, P. and Ermelinda Camilo, M. (2005) Impact of Nutrition on Outcome: A Prospective Randomised Controlled Trial in Patients with Head and Neck Cancer Undergoing Radiationtherapy. Head \& Neck, 27, 659-668. http://dx.doi.org/10.1002/hed.20221

[13] Ravasco, P., Monteiro-Grillo, I., Vidal, P. and Camilo, M. (2005) Dietary Counseling Improves Patient Outcomes: A Prospective, Randomised Controlled Trial in Colorectal Cancer Patients Undergoing Radiotherapy. Journal of Clinical Oncology, 23, 1431-1438. http://dx.doi.org/10.1200/JCO.2005.02.054

[14] Stat Trek (2011) Random Number Generator. http://stattrek.com/statistics/random-number-generator.aspx

[15] Ferguson, M., Capra, S., Bauer, J. and Banks, M. (1999) Development of a Valid and Reliable Malnutrition Screening Tool for Adult Acute Hospital Patients. Nutrition, 15, 458-464. http://dx.doi.org/10.1016/S0899-9007(99)00084-2

[16] Kubrak, C. and Jensen, L. (2007) Critical Evaluation of Nutrition Screening Tools Recommended for Oncology Patients. Cancer Nursing, 30, E1-E6. http://dx.doi.org/10.1097/01.NCC.0000290818.45066.00

[17] Watterson, C., Fraser, A., Banks, M., Isenring, E., Miller, M., Silvester, C., et al. (2009) Evidence Based Practice Guidelines for the Nutritional Management of Malnutrition in Adult Patients across the Continuum of Care. Dietitians Association of Australia (DAA), Deakin.

[18] Amaral, T., Antunes, A., Cabral, S., Alves, P. and Kent-Smith, L. (2008) An Evaluation of Three Nutritional Screening Tools in a Portugese Oncology Centre. Journal of Human $\mathrm{Nu}$ trition and Dietetics, 21, 575-583. http://dx.doi.org/10.1111/j.1365-277X.2008.00917.x

[19] Ottery, D. (2000) Patient Generated Subjective Global Assessment. In: McCallum, P. and Polisena, C., Ed., The Clinical Guide to Oncology Nutrition, The American Dietetic Association, Chicago, 11-23.

[20] Sensis (2011) Whereis. http://www.whereis.com

[21] Isenring, E., Zabel, R., Bannister, M., Brown, T., Findlay, M., Kiss, N., et al. (2013) Updated Evidence Based Practice Guidelines for the Nutritional Management of Patients Receiving 
Radiation Therapy and/or Chemotherapy. Nutrition \& Dietetics, 70, 312-324. http://dx.doi.org/10.1111/1747-0080.12013

[22] Davidson, W., Isenring, E., Brown, T. and Riddle, B. (2006) Nutritional Management of Patients with Head and Neck Cancer: Integrating Research into Practice. Cancer Forum, 30, 183-187.

[23] Marin-Caro, M., Laviano, A. and Pichard, C. (2007) Nutrition Intervention and Quality of Life in Adult Oncology Patients. Clinical Nutrition, 26, 289-301. http://dx.doi.org/10.1016/j.clnu.2007.01.005

[24] Van-Custem, E. and Arends, J. (2005) The Causes and Consequences of Cancer Associated Malnutrition. European Journal of Oncology Nursing, 9, s51-s63. http://dx.doi.org/10.1016/j.ejon.2005.09.007

[25] Shaw, C., Fleurent, C., Pickard, J., Mohammed, K., Black, G. and Wedlake, L. (2015) Comparison of a Novel, Simple Nutrition Screening Tool for Adult Oncology Inpatients and the Malnutrition Screening Tool (MST) against the Patient Generated Subjective Global Assessment (PG-SGA). Supportive Care in Cancer, 23, 47-54.

http://dx.doi.org/10.1007/s00520-014-2319-8

[26] Planas, M., Alvarez-Hernandez, J., Leon-Sanz, M., Celaya-Perez, S., Araujo, K. and Garcia De Lorenzo, A. (2016) Prevalence of Hospital Malnutrition in Cancer Patients: A SubAnalysis of the PREDYCES Study. Supportive Care in Cancer, 24, 429-435. http://dx.doi.org/10.1007/s00520-015-2813-7

[27] Abbott, J., Teleni, L., McKavanagh, D. and Watson, J. (2014) A Novel, Automated Nutrition Risk Screening System as a Predictor of Nutritional Risk in an Oncology Day Treatment Unit (Odtu). Supportive Care in Cancer, 22, 2107-2112. http://dx.doi.org/10.1007/s00520-014-2210-7

[28] Leon-Sanz, M., Brosa, M., Planas, M., Garcia-de-Lorenzo, A., Celaya-Perez, S. and Alvarez Hernandez, J. (2015) Predyces Study: The Cost of Hospital Malnutrition in Spain. Nutrition, 31, 1096-1102. http://dx.doi.org/10.1016/j.nut.2015.03.009

[29] Mattson, J. (2010) Transportation, Distance and Healthcare Utilization for Older Adults in Rural and Small Urban Areas. Upper Great Plains Transportation Institute, North Dakota State University, Fargo.

[30] Humphreys, J. and Wakerman, J. (2009) Primary Health Care in Rural and Remote Australia: Achieving Equity of Access and Outcomes through National Reforms. http://www.health.gov.au/internet/nhhrc/publishing.nsf/Content/16F7A93D8F578DB4CA2 574D7001830E9

[31] Syed, S., Gerber, B. and Sharp, L. (2013) Traveling towards Disease: Transportation Barriers to Health Care Access. Journal of Community Health, 38, 976-993. http://dx.doi.org/10.1007/s10900-013-9681-1

[32] Nemet, G. and Bailey, A. (2000) Distance and Healthcare Utilization among the Rural Elderly. Social Science and Medicine, 50, 1197-1208. http://dx.doi.org/10.1016/S0277-9536(99)00365-2

[33] Winters, C., Cudney, S., Sullivan, T. and Thuesen, A. (2006) The Rural Context and Women's Self-Management of Chronic Health Conditions. Chronic Illness, 2, 273-289. http://dx.doi.org/10.1177/17423953060020040801

[34] NSW Department of Health (2010) Radiotherapy Services in NSW: Strategic Plan to 2016. Sydney. 
Submit or recommend next manuscript to SCIRP and we will provide best service for you:

Accepting pre-submission inquiries through Email, Facebook, LinkedIn, Twitter, etc. A wide selection of journals (inclusive of 9 subjects, more than 200 journals)

Providing 24-hour high-quality service

User-friendly online submission system

Fair and swift peer-review system

Efficient typesetting and proofreading procedure

Display of the result of downloads and visits, as well as the number of cited articles

Maximum dissemination of your research work

Submit your manuscript at: http://papersubmission.scirp.org/

Or contact fns@scirp.org 